\title{
MAPPING IMPACT OF DESIGN THINKING IN TEAMWORK, PROBLEM-SOLVING AND CREATIVITY
}

\author{
S. Guaman-Quintanilla ${ }^{1,2, \otimes}$, K. Chiluiza ${ }^{1}$, P. Everaert ${ }^{2}$ and M. Valcke ${ }^{2}$ \\ ${ }^{1}$ Escuela Superior Politécnica del Litoral, Ecuador, ${ }^{2}$ Ghent University, Belgium \\ $\square$ seguaman@espol.edu.ec
}

\begin{abstract}
The present study analyzes the impact of a Design Thinking course on undergraduate students during an academic term. The impact was measured on three key outcomes: teamwork, problemsolving and creativity; using VALUE rubrics. The evaluation was carried out at three different moments during the course. Three types of evaluators participated: facilitators, students (selfevaluation) and peers. The results show statistically significant improvement on the three outcomes comparing students' initial and final performance. Despite the promising results, the current study has some limitations.
\end{abstract}

Keywords: design thinking, teamwork, problem solving, creativity, empirical studies

\section{Introduction}

Universities around the world have invested considerable effort to prepare their students with the skills demanded by the 21st Century organizations (Lamb et al., 2017). In this regard, Design Thinking (DT) has captured the eye of many Higher Education Institutions offering DT-embed courses throughout the curriculum. One of the most popular definition, describes DT as "a discipline that uses the designer's sensibility and methods to match people's needs with what is technologically feasible and what a viable business strategy can convert into customer value and market opportunity" (Brown, 2008, p. 2). There are authors that suggest DT is based on earlier models, such as the Conceiving, Designing, Implementing, Operating (CDIO) framework and Problem Based Learning (PBL) which have been part of engineering schools practices (Spee and Basaiawmoit, 2016). Literature shows that in the last decade DT has gained popularity in Higher Education contexts (Spee and Basaiawmoit, 2016), (Razzouk and Shute, 2012), (Liedtka, 2014), (Fleury et al., 2016), (Kleinsmann et al., 2017), (Matthews and Wrigley, 2017); however those studies barely addressed the impact on students' outcomes. Authors have argued lack of a systematic assessment of DT results (Liedtka, 2014), as well as lack of accurate, performancebased measures of DT (Razzouk and Shute, 2012). This is also supported by Spee and Basaiawmoit (2016) who critic the absence of statistically robust empirical studies about the effectiveness of DT in producing consistent learning outcomes. Steinbeck (2011) urges the development of comprehensive DT assessment approaches that fit the complex nature of DT, and its application in multidisciplinary settings. A review carried out by the authors shows that most-mentioned outcomes of DT in Higher Education contexts are teamwork, problem-solving e.g. (Matsushita et al., 2015), (Lugmayr et al., 2014), (Parmar, 2014), (Taajamaa et al., 2013), and creativity/creative thinking e.g. (West et al., 2012), (Saggar et al., 2017), (Clemente et al., 2017), (Benson and Dresdow, 2015), among others. 
Nevertheless, empirical evidence on theses outcomes is hardly convincing, this explain our focus on these variables by setting up an empirical quantitative study. Therefore, this study aims to answer the following research question: What is the DT impact on teamwork, problem-solving and creativity of students in Higher Education?

\subsection{Context of the study}

Since 2016, Escuela Superior Politecnica del Litoral (ESPOL) offers a DT course, under the name of Analysis and Problem Solving (APS onwards). This is a compulsory course for all freshmen students. Each academic term, ESPOL offers 20-35 APS course sections; each class has up to 35 students. In this course students work in multi-disciplinary teams (5-7 students) solving a real problem during the whole academic term, each team has a different problem. The problems are mostly suggested by NGOs or small businesses which are called 'sponsors'. APS course uses an adapted DT approach (Santos Ordóñez et al., 2017) which is based on the model presented by the Hasso-Plattner Institute of Design at Stanford (d.school) (Hasso-Plattner-Institut, n.d.) and the UK's Design Council four-step process, also known as the "Double Diamond" model (Design Council, 2007). APS course is comprised of 32 sessions of 90 minutes each: 2 sessions ( 3 hours) per week. Additionally, the course requires 6 hours of autonomous work per week, most of it in teams. All the contents, activities, grading policy are the same for all APS course sections; so, facilitators meet often to check the course progress. There is no written exam, the main product of this course is a project by which each team presents the solution proposal for the assigned problem. The other courses in the first semester are mainly focused on foundation knowledge instead of the development of soft skills such as teamwork, problem-solving and creativity. The course is divided in two parts. During the first part, students learn and apply tools and techniques corresponding to the following stages in the adapted DT approach used in the APS course:

- Research Stage: Actors map, context interviews, observation.

- Empathy Stage: Forced priorities, context interviews, journey maps, customer's empathy map.

- Define Stage: Clustering, Buyer Persona, Point of View

Once the three first phases are completed, all students must take the First Exam which consists of a team presentation about the progress of their projects. For the second part of the course, students learn and apply tools and techniques corresponding to the last three stages of the DT approach:

- Ideate Stage: Brainwriting, Analogies, Upside down, Systematic Inventive Thinking, ImpactDifficulty matrix, IPOS table.

- Prototype Stage: Sketching, Mock-Ups, Storyboards, Roleplay, Turkish automaton, Smokescreen, One-night performance, false interface, 3D printing, mock-ups app, mock-ups website, environment recreation.

- Validation Stage: Feedback matrix

At the end of the course, students prepare a team presentation, as final exam, where they explain the solution proposal as a result of applying DT. All sponsors are invited to these presentations; however not all of them are always able to attend. In view of the study, the set up was standardized.

\section{Theoretical and conceptual base}

The use of DT in education fit in the theory of Constructivism (Noweski et al., 2012). Constructivism focuses on the processes by which learners build their own mental structures from an interaction between their experiences and their ideas (Piaget, 1954). These theories favor hands-on, task-oriented, self-directed activities aimed to design and discovery (Wenger, 2009). Given the characteristics of APS course's activities which are oriented towards discovery and definition of problems/opportunities as well as the design of user-centered solutions, the course follows the approach of Constructivism educational strategies. Likewise, APS course seeks to engage students in the solution of real problems using a human-centered approach, they involve as active participants in the practices of social communities, developing empathy as a result of their dive-in experiences in real contexts, constructing 
identities in relation to these communities. Hence, we can relate DT to a social theory of learning proposed by Wenger (2009) that focuses on learning as social participation. He defines participation beyond mere engagement in activities with people, but as "a more encompassing process of being active participants in the practices of social communities and constructing identities in relation to these communities (...) Such participation shapes not only what we do, but also who we are and how we interpret what we do" (Wenger, 2009, p. 210-211). As aforementioned, literature shows that some of the DT most related outcomes are teamwork, problem-solving and creativity. Those outcomes are also connected to the so called 21st Century Skills (Wagner, 2010) (Lamb et al., 2017). There are several definitions about teamwork, problem-solving and creativity; as well as instruments to measure them. As a result of a literature review, we decided to use the VALUE (Valid Assessment of Learning in Undergraduate Education) rubrics developed by faculty experts (AAC\&U, 2009a). The VALUE rubrics provide a definition for each of the following; that are also the key outcomes as could be derived from the review of the literature:

- Teamwork: "Behaviors under the control of individual team members (effort they put into team tasks, their manner of interacting with others on team, and the quantity and quality of contributions they make to team discussions.)" (AAC\&U, 2009b)

- Problem-solving: "The process of designing, evaluating and implementing a strategy to answer an open-ended question or achieve a desired goal. " (AAC\&U, 2009c)

- Creative thinking (Creativity onwards): "It is both the capacity to combine or synthesize existing ideas, images, or expertise in original ways and the experience of thinking, reacting, and working in an imaginative way characterized by a high degree of innovation, divergent thinking, and risk taking." (AAC\&U, 2009d).

\section{Research design}

This study follows a quantitative approach collecting data in three periods $(\mathrm{t} 0, \mathrm{t} 1, \mathrm{t} 2)$. We used a multiple actor perspective as evaluators of the outcomes: student as self-evaluator, peers and course's facilitator.

\subsection{Research hypothesis}

To answer our research question, we put forward the following hypotheses:

Hypothesis 1: Students under a Design Thinking intervention improve their teamwork skills throughout the study.

Hypothesis 2: Students under a Design Thinking intervention improve their problem-solving skills throughout the study.

Hypothesis 3: Students under a Design Thinking intervention improve their creativity skills throughout the study.

\subsection{Participants}

The sample consisted of 4 sections of APS course, in total $\mathrm{N}=136$ freshmen students, 100 males, 35 females, one did not report gender information. 83\% of the students had no working experience and $93 \%$ were enrolled in an undergraduate engineering program. Informed consent was obtained from all students after ethical clearance from university authorities. Each course section had 1 facilitator, so 4 facilitators participated. These sections/facilitators were selected based on their voluntary participation. To minimize risk of bias, facilitators were informed about the research study beforehand. It was clearly explained that the results would not be taken as an indicator of facilitators' performance; neither the results would be presented by course/facilitator. Students were also informed that their participation in this study would not help them to get extra points, nor get any penalization.

\subsection{Research instruments}

Before the intervention, we conducted meetings with the facilitators involved in the study and a couple of undergraduate students who had not taken the APS course before (not involved in the current study) 
to review the research instruments and test-taking steps. This procedure helped to check language and translation issues, as well as consisting interpretations, that directed the development of a final version of the instruments for all three outcomes: teamwork, problem-solving and creativity. To assess the three outcomes, we used the VALUE rubrics (AAC\&U, 2009a). VALUE rubrics report holding two types of validity (Finley, 2012). First, they hold a high degree of face validity as they were created by American teams of faculty who were familiar to student learning and outcomes assessment on colleges and universities, this means the rubrics. Second, additional content validity to the rubrics was obtained by the participation of faculty experts in particular outcome areas (Finley, 2012). Furthermore, the face validity of the rubrics could be also supported by the scale of interest and circulation of the rubrics, indicated by more than 70,000 people who accessed the rubrics as of December 2015, from more than 5,895 institutions, including colleges and universities (AAC\&U, 2009a). Regarding to reliability, according to Rhodes (2012) the inter-rater reliability results reported that some VALUE rubrics exceeded the 0.8 standard routinely used for such measures. Finally, Rhodes and Finley (2013) found that Carroll Community College, DePaul University, Midland College, and Texas A\&M University all reported high inter-rater reliability results among faculty scorers. The VALUE rubrics for teamwork, problem-solving and creativity were translated to Spanish. In the case of creativity and problem-solving rubrics, we omitted 1 and 2 items, respectively, as those are not supposed to fit into the scope of the APS course. Each rubric has 5 performance levels (A, B, C, D, E) were A represents the highest score and $\mathrm{E}$ the lowest. Students, peers and facilitators used the VALUE rubrics for evaluating the three outcomes. For teamwork, the perceived performance inside the teams was evaluated, using the 5-item VALUE rubric for teamwork (AAC\&U, 2009b), which was called Rubric A in this study. These items were: i) Contributes to team meetings, ii) Facilitates the contributions of team members, iii) Individual contributions outside of team meetings, iv) Fosters constructive team climate, v) Responds to conflict. Problem-solving and creativity were evaluated by students, peers and facilitator based on the answers' content about a case study (case and questions can be accessed upon request to the authors). Evaluators used a 4-item VALUE rubric for problem solving (AAC\&U, 2009c) and a 5-item VALUE rubric for creativity (AAC\&U, 2009d). Both rubrics' items were joined in the same table which was called Rubric $B$ in this study. The items in the problem-solving rubric were: i) Define problem, ii) Identify strategies, iii) Propose solutions, iv) Evaluate potential solutions. The items for Creativity were: i) Acquiring Competencies, ii) Taking Risks, iii) Embracing Contradictions, iv) Innovative Thinking, v) Connecting, Synthesizing, Transforming.

Additionally, a questionnaire to collect background data from students was taken at t0, t1, t2.

\subsection{Procedure}

The study took place during the second semester of the academic year 2018-2019 (from October 2018 to February 2019), 14 weeks distributed in 28 sessions in total. The setting for the intervention was 4 sections of the APS course. Before the intervention, four facilitators agreed to participate voluntarily in this study doing the activities - in class and out of class - for the duration of the study, which included taking the tests and grading as one of the evaluators for the three outcomes (teamwork, problem-solving, creativity). Data was collected three times throughout the semester: $\mathrm{t} 0, \mathrm{t} 1, \mathrm{t} 2$, during face-to-face classes. The first one (t0) was taken in the first week of classes. $\mathrm{t} 1$ was taken in week 8 , just the week after the first exam, at that point students had learned first three DT phases: Research, Empathy, Define. Finally, t2 was taken on the final week (week 14), by then students had completed the last three phases: Ideate, Prototype, Validation; the next week students had their final exam. Each collection session lasted about 60-75 minutes. Data collection was done using paper-based forms.

The intervention started at $\mathrm{t} 0$, students signed a consent letter, then they filled out a questionnaire about background information (gender, age, academic program, level of expectation about the APS course, level of academic stress, etc.). Next, students answered the case study questions on a form; right after that, students assessed 1 peer's form, randomly assigned, using Rubric B (to score problemsolving and creativity). Then, students evaluated their own answers using Rubric B, too. At the end of the session, facilitators collected all forms and took home the case study answers to evaluate them using Rubric B templates. Since there is no information available, teamwork was not assessed at t0. 
At $\mathrm{t} 1$ and $\mathrm{t} 2$ the following procedure was applied: First, students filled out a questionnaire to follow-up certain information such as: number of courses taken during the semester, number of expected hours student dedicated to APS weekly, level of expectation about APS course and, level of academic stress they felt when filling out the questionnaire. After that, students evaluated their own performance in their teams using the Rubric A. Due to time constraints, students took home an extra Rubric A template for evaluating each of their team members, this implies that, when processing the data, each student received an average score that came from evaluations carried out by all his/her team members. Teams remained the same during the whole study. Next, students answered the same case study questions on a form; right after that, students assessed 1 peer's form, randomly assigned, using Rubric B. Then, students evaluated their own answers. At the end of the session, facilitators collected all forms and took home the case answers to evaluate them using the Rubric B templates, facilitators also took home Rubric A templates to assess their students' teamwork performance.

\subsection{Analysis approach}

We used SPSS (version 25) to conduct the analyses. For hypothesis testing, we carried out Within group repeated measures ANOVA to detect any overall differences in mean scores over the three time points ( $\mathrm{t} 0, \mathrm{t} 1, \mathrm{t} 2)$. A reliability analysis was carried out using Cronbach's Alpha for the 5-item Teamwork rubric, 4-item Problem-solving rubric and 5-item Creativity rubric, for each type of evaluator. In general terms, Cronbach's alpha showed the rubrics' items reached acceptable reliability scores. None of the rubrics' items were removed because the differences were not significant to make the rubrics more reliable. An exploratory factor analysis using the principal component analysis extraction method was conducted to determine the factor structure of the three rubrics' items. The rotation method used was Varimax with Kaiser Normalization. We took the case of facilitators' scores at $\mathrm{t} 1$ for teamwork, problem-solving and creativity rubrics' items. Factor 1 is comprised of 5 items, reported on a 5-level performance, with factor loadings from 0.903 to 0.925 ; this structure coincides with the items of teamwork rubric. Factor 2 is comprised of 6 items, reported on a 5-level performance, with factor loadings from 0.539 to 0.858 ; this structure coincides with the items of creativity rubric, except the item "Evaluate Potential Solutions" which belongs to problem-solving rubric. Nevertheless, we decided to leave this item in the problem-solving rubric. Factor 3 is comprised of 3 items, reported on a 5-level performance, with factor loadings from 0.663 to 0.855 ; this structure coincides with the items of problem-solving rubric, except the item mentioned before.

\section{Results}

\subsection{Descriptive Information of background variables}

When analyzing mean and standard deviations for background variables, we noticed changes throughout the study. At the beginning of the course, students expected to dedicate 4.35 hours to the APS course, however they reported a dedication of 3.80 hours, at $\mathrm{t} 2$. Level of expectation about the course started at 7.86 (in a 1-10 scale) and ended at 6.76. Finally, students' academic stress increased from 5.52 at to to 6.53 at $\mathrm{t} 2$.

\subsection{Hypothesis 1: Students under a Design Thinking intervention improve their teamwork skills throughout the study}

We conducted a within group repeated measures ANOVA to test any significant differences in teamwork mean scores over the two time points $(\mathrm{t} 1, \mathrm{t} 2)$ for each type of evaluators. In the case of students' self-evaluation, this test reflected no significant effect $F(1,101)=2.529, p=0.115$. However, in the case of peers' evaluation there was a significant difference $\mathrm{F}(1,131)=27.432$, $\mathrm{p}<$ 0.001 . Statistical analysis revealed that teamwork was not significantly different in facilitators evaluation $\mathrm{F}(1,133)=0.197, \mathrm{p}=0.658$. Students improved their teamwork skills, there were positive differences in mean scores between $\mathrm{t} 2$ and $\mathrm{t} 1$ : self-evaluation (0.08) and peer evaluation (0.16), facilitators mean scores did not change. Nevertheless, only the improvement scored by peers was statistically significant. Hence, only in the case of peers' evaluation we reject the null hypothesis and 
accept H1: Students under a Design Thinking intervention improve their teamwork skills throughout the study.

Since peers and facilitators performed a similar role as evaluators of students during the study, we wanted to know whether there was a correlation at each time. We found there was a positive and significant correlation at $\mathrm{t} 1$ between peers and facilitators when assessing teamwork $\mathrm{r}=0.572, \mathrm{n}=$ $134, \mathrm{p}<0.001$. At $\mathrm{t} 2$ there is also a positive and significant correlation between these two evaluators $\mathrm{r}$ $=0.488, \mathrm{n}=132, \mathrm{p}<0.001$.

\subsection{Hypothesis 2: Students under a Design Thinking intervention improve their problem-solving skills throughout the study}

We ran the repeated measures (within-subjects) ANOVA to identify whether at least two problemsolving score means are significantly different over the three time points $(\mathrm{t} 0, \mathrm{t} 1, \mathrm{t} 2)$ for each type of evaluators. The omnibus statistical output for students' evaluation scores is significant $\mathrm{F}(2,182)=$ $25.133, \mathrm{p}<0.001$. We were interested in taking a closer look of the tests of within-subjects contrasts, so we found that from t0 to $t 2$ the difference was significant $F(1,91)=35.551, \mathrm{p}<0.001$ while from $\mathrm{t} 1$ to $\mathrm{t} 2$ the difference was not significant $\mathrm{F}(1,91)=0.016, \mathrm{p}=0.899$. The omnibus statistical output for peers' evaluation scores is also significant $\mathrm{F}(2,186)=15.449, \mathrm{p}<0.001$. When we tested the change between $\mathrm{t} 0$ to $\mathrm{t} 2$ we found a significant difference $\mathrm{F}(1,93)=28.520, \mathrm{p}<0.001$ while from $\mathrm{t} 1$ to $\mathrm{t} 2$ the difference was not significant $F(1,93)=3.126, p=0.080$. The scores given by facilitators reflect that the omnibus ANOVA is also significant $F(2,200)=42.269, \mathrm{p}<0.001$. When analyzing to to 2 the difference was significant $\mathrm{F}(1,100)=47.612, \mathrm{p}<0.001$ however, the difference between $\mathrm{t} 1$ and $\mathrm{t} 2$ was not significant $\mathrm{F}$ $(1,100)=1.136, p=0.289$. To complement our analysis, Figure 1 reflects how students developed their problem-solving scores according to all evaluators (students, peers, facilitators). It is evident the improvement from t0 to t 2 in all cases, which is confirmed by the statistical significance showed previously. Therefore, we reject the null hypothesis and accept H2: Students under a Design Thinking intervention improve their problem-solving skills throughout the study. The latter applies for all evaluators scores. Figure 1 also shows a decline in performance means between $\mathrm{t} 1$ and $\mathrm{t} 2 \mathrm{in}$ students and facilitators scores, nevertheless the analysis showed that difference is not significant.

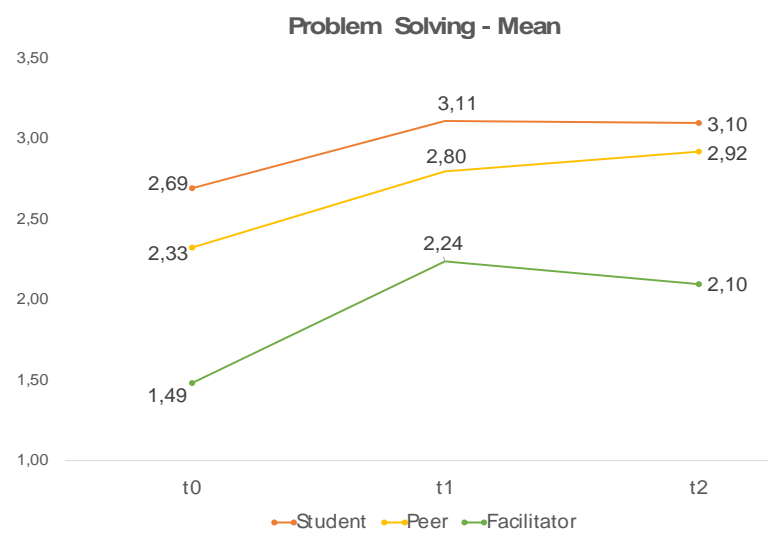

Figure 1. Problem-solving mean scores at $\mathrm{t} 0, \mathrm{t} 1$ and $\mathrm{t} 2$

As mentioned before, we were interested to check whether there was a correlation between peers and facilitators scoring at each time. The analysis showed there was a positive and significant correlation when assessing problem-solving at $\mathrm{t} 0 \mathrm{r}=0.225, \mathrm{n}=134, \mathrm{p}=0.009$. At $\mathrm{t} 1$, there was also a positive and significant correlation between these two evaluators $\mathrm{r}=0.198, \mathrm{n}=110, \mathrm{p}=0.038$. Finally, at $\mathrm{t} 2$ the correlation was also positive and significant $\mathrm{r}=0.386, \mathrm{n}=108, \mathrm{p}<0.001$.

\subsection{Hypothesis 3: Students under a Design Thinking intervention improve their creativity skills throughout the study}

Similar as previous analysis approach, we conducted a within group repeated measures ANOVA to test whether at least two creativity score means are significantly different over the three time points 
$(\mathrm{t} 0, \mathrm{t} 1, \mathrm{t} 2)$ for each of evaluators. The omnibus statistical output for students' evaluation scores was significant $\mathrm{F}(2,184)=25.678, \mathrm{p}<0.001$. When running tests of within-subjects contrasts, we found that the difference from t0 to $t 2$ was significant $F(1,92)=41.748, p<0.001$ while from t 1 to $t 2$ was not significant $F(1,92)=4.791, p=0.031$. Likewise, the omnibus statistical output for peers' evaluation scores is also significant $F(2,194)=11.131, \mathrm{p}<0.001$. The peers' scores between t0 to t2 presented a significant change $\mathrm{F}(1,97)=18.041, \mathrm{p}<0.001$ while t 1 to $\mathrm{t} 2$ the difference was not significant $\mathrm{F}(1,97)=2.435, \mathrm{p}=0.122$. In the case of facilitators' scores, the omnibus ANOVA reflected a significant variation $\mathrm{F}(2,196)=43.755, \mathrm{p}<0.001$. When analyzing to to t 2 the difference was significant $\mathrm{F}(1,98)=49.183, \mathrm{p}<0.001$ however, the difference between $\mathrm{t} 1$ and $\mathrm{t} 2$ was not significant $F(1,98)=3.744, p=0.056$. Figure 2 shows creativity mean scores throughout the study according to students, peers and facilitator. Visually there is an improvement from to to t 2 in all cases, which is confirmed by the statistical significance presented previously. Therefore, we reject the null hypothesis and accept H3: Students under a Design Thinking intervention improve their creativity skills throughout the study. Figure 2 also shows a decline in facilitators' scores between $\mathrm{t} 1$ and $\mathrm{t} 2$, however the analysis showed that difference is not significant.

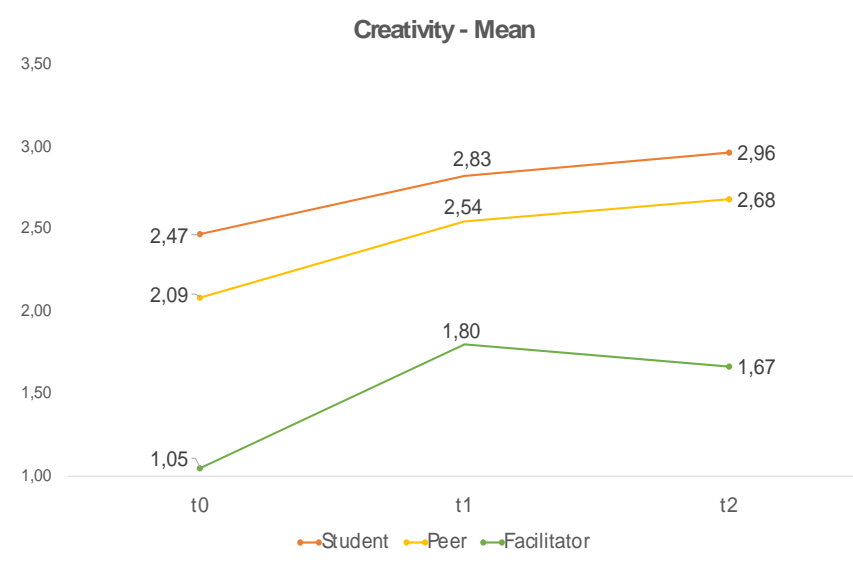

Figure 2. Creativity mean scores at $\mathrm{t} 0, \mathrm{t} 1$ and $\mathrm{t} 2$

Finally, when testing correlation between peers and facilitators scoring, the results showed there is a positive and significant correlation when assessing creativity at $\mathrm{t} 0 \mathrm{r}=0.198, \mathrm{n}=110, \mathrm{p}=0.038$. At $\mathrm{t} 1$, there is also a positive and significant correlation between these two evaluators $\mathrm{r}=0.386, \mathrm{n}=108, \mathrm{p}<$ 0.001 . At $\mathrm{t} 2$ the correlation is also positive and significant $\mathrm{r}=0.237, \mathrm{n}=108, \mathrm{p}=0.013$.

\section{Discussion}

The results of this study contribute to research about outcomes related to DT in Higher Education settings because of the availability of the design and related measurement instruments that can be adopted by other universities. Unfortunately, our findings cannot be contrasted with a control group; however, that does not hinder the value of the results that goes beyond the available studies by following a robust empirical research about the effectiveness of DT.

First, regarding hypothesis 1, teamwork is the outcome which could be analyzed in two time periods $(\mathrm{t} 1, \mathrm{t} 2)$, only. The results show that students under a DT intervention improved their teamwork skills throughout the study, when analyzing their peers' scores. Other studies also found positive impact when assessing the impact of a DT intervention on teamwork (Lugmayr et al., 2014), (Valentim et al., 2017), (Benson and Dresdow, 2015), (Matsushita et al., 2015), (Parmar, 2014), (Taajamaa et al., 2013), (Khalaf et al., 2012), (Palacin-Silva et al., 2017). On the other hand, hypothesis 1 could not be accepted when analyzing facilitators' scores and students' self-evaluation. Nevertheless, these results could be explained since facilitators did not have enough information about students' performance inside the teams. Most teachers are unable to know what happens during teams' interaction (Strom et al., 1999). In the case of students' self-evaluation, hypothesis 1 could not be supported either, students' scores were lower than peers' evaluation and higher than facilitators evaluation. In the 
literature we found studies that reported no impact on teamwork after a DT intervention using selfevaluation instruments (Ohly et al., 2016), (Suh et al., 2014); and one reported a negative impact after collecting data from a student survey (Gatchell et al., 2014).

Second, regarding Hypothesis 2 we accept that students under a DT intervention improved their problem-solving skills throughout the study. Since DT is related to problem-solving as one of its key elements (Dorst, 2011), (Liedtka, 2014), (Fleury et al., 2016), we expected a confirmation of our hypotheses. But different from the available literature, our hypotheses testing was based on specifically design instruments in a controlled environment. As such, behavioural indicators are being put forward to support this often generally claimed impact on problem-solving. Furthermore, there are other studies that reported positive impact on problem-solving skills after a DT intervention (Lugmayr et al., 2014), (Bhatnagar and Badke-Schaub, 2017), (Alhamdani, 2016), (Anand et al., 2015), (Matsushita et al., 2015), (Taajamaa et al., 2013), (Khalaf et al., 2012), (Parmar, 2014). It is worth to draw attention to the decrease in facilitators' mean scores from t1 to t2 (Figure 1), despite this change is not significant, it might be explained by the fact that teachers' expectations create biases in evaluation of students (Jussim, 1989); and facilitators verbally reported that their expectations were higher at the end of the course than at the mid-term.

Third, hypothesis 3 was also supported by students, peers and facilitators scores when comparing t0 vs t2. In this regard, the results show that students under a DT intervention improved their creativity skills throughout the study. Some studies also found a positive impact on this outcome after a DT intervention (West et al., 2012), (Saggar et al., 2017), (Clemente et al., 2017), (Benson and Dresdow, 2015), and one reported no impact (Ohly et al., 2016). The decline on facilitators mean score from t1 to 2 showed in Figure 2 is not significant; however, it can also be explained by the higher facilitators' expectations by the end of the course.

Fourth, we want to shed light on the correlation among peers and facilitators. In all cases these two type of evaluators, who shared more or less the same role, seemed to agree on the way of scoring throughout the study, it means at $\mathrm{t} 0, \mathrm{t} 1$ and $\mathrm{t} 2$. The latter adds information about the internal consistency of the instruments.

\section{Limitations and future study}

Despite the promising results, the current study has limitations. First, this study did not have a control group because APS course is mandatory for all freshmen students. Second, though the facilitators' profiles were appropriate, they were chosen based on their collaborative profile and they accepted to participate voluntarily. This could have introduced bias. Third, this study does not measure the impact of participants' background (type of high school, level of income, personal traits, etc.) on the results. Fourth, the research question has been answered from a quantitative point of view, only. It is suggested to complement the study with a qualitative analysis. Finally, we acknowledge the need for involving a larger sample to obtain results with sufficient power for generalization. Nevertheless, this study contributed to present a stronger methodological research design since it includes the vision of three different actors in the evaluation process in comparison to other studies where most of the findings were anecdotical or based mainly on students' self-reports. The former inspires future research directions. First, we need to extent the sample size as well as the numbers of facilitators. Second, we should apply the same study in another course, different from APS, in order to make sure that the results are not just an effect of regular students' maturity along the semester. Third, we can attempt to have an integrated score for the outcomes that comprehensively includes the individual scores of evaluators. Fourth, we should include more background information about students to explain how individual characteristics might affect the results.

\section{Acknowledgments}

We would like to acknowledge ESPOL's i3lab-Entrepreneurship and Innovation Center for administrative support. Also, our acknowledgment to facilitators and students for the support to carry out the intervention. Furthermore, this research received no specific grant from any funding agency in the public, commercial, or notfor-profit sectors. 


\section{References}

Alhamdani, W.A. (2016), "Teaching Cryptography Using Design Thinking Approach”, Journal of Applied Security Research, Routledge, Vol. 11 No. 1, pp. 78-89.

Anand, A. et al. (2015), "Generation of Educational Technology Research Problems Using Design Thinking Framework", 2015 IEEE Seventh International Conference on Technology for Education (T4E), IEEE, pp. 69-72.

AAC\&U-Association of American Colleges \& Universities. (2009a), “What is VALUE?”, VALUE, available at: https://www.aacu.org/value (accessed 20 September 2011).

AAC\&U-Association of American Colleges \& Universities. (2009b), "Teamwork VALUE Rubric".

AAC\&U-Association of American Colleges \& Universities. (2009c), "Problem Solving VALUE Rubric", available at: https://www.aacu.org/value/rubrics/problem-solving

AAC\&U-Association of American Colleges \& Universities. (2009d), "Creative Thinking VALUE Rubric", available at: https://www.aacu.org/value/rubrics/creative-thinking

Benson, J. and Dresdow, S. (2015), "Design for Thinking: Engagement in an Innovation Project", Decision Sciences Journal of Innovative Education, Wiley/Blackwell (10.1111), Vol. 13 No. 3, pp. 377-410.

Bhatnagar, T. and Badke-Schaub, P. (2017), "Design Thinking and Creative Problem Solving for Undergraduate Engineering Education in India: The Need and Relevance BT - Research into Design for Communities, Volume 2", In: Chakrabarti, A. and Chakrabarti, D. (Eds.), Springer Singapore, Singapore, pp. 953-967.

Brown, T. (2008), "Design Thinking”, Harvard Business Review, pp. 84-92.

Clemente, V., Tschimmel, K. and Vieira, R. (2017), "Why a Logbook? A backpack journey as a metaphor for product design education”, The Design Journal, Routledge, Vol. 20 No. sup1, pp. S1530-S1542.

Design Council. (2007), "Eleven lessons: managing design in eleven global companies", Desk research report, Vol. 44 No. 272099, p. 18.

Dorst, K. (2011), “The core of 'design thinking' and its application”, Design Studies, Elsevier, Vol. 32 No. 6 , pp. 521-532.

Finley, A.P. (2012), "How reliable are the VALUE rubrics?", Peer Review Published by the Association of American Colleges and Universities, Washington, Vol. 13 No. 4, pp. 31-33.

Fleury, A., Stabile, H. and Carvalho, M. (2016), "An Overview of the Literature on Design Thinking: Trends and Contributions", International Journal of Engineering Education, Vol. 32.

Gatchell, D.W. et al. (2014), "Restructuring teamwork pedagogy in a first-year engineering design program: Lessons learned and future plans", 121st ASEE Annual Conference and Exposition: 360 Degrees of Engineering Education, American Society for Engineering Education.

Hasso-Plattner-Institut. (n.d.), "What is Design Thinking?", available at: https://hpi.de/en/school-of-designthinking/design-thinking/what-is-design-thinking.html

Jussim, L. (1989), "Teacher Expectations: Self-Fulfilling Prophecies, Perceptual Biases, and Accuracy”, Journal of Personality and Social Psychology, Vol. 57, pp. 469-480.

Khalaf, K. et al. (2012), "Engineering design education: Towards design thinking", Interactive Collaborative Learning (ICL), 2012 15th International Conference On, IEEE, pp. 1-4.

Kleinsmann, M., Valkenburg, R. and Sluijs, J. (2017), "Capturing the Value of Design Thinking in Different Innovation Practices", International Journal of Design, Vol. 11, p. 2, (2017), available at: http://ijdesign. org/index.php/IJDesign/article/view/2771/780

Lamb, S., Maire, Q. and Doecke, E. (2017), Key Skills for the 21st Century: An Evidence-Based Review.

Liedtka, J. (2014), "Perspective: Linking Design Thinking with Innovation Outcomes through Cognitive Bias Reduction", Journal of Product Innovation Management, Wiley/Blackwell (10.1111), Vol. 32 No. 6, pp. 925-938.

Lugmayr, A. et al. (2014), “Applying 'Design Thinking' in the context of media management education”, Multimedia Tools and Applications, Vol. 71 No. 1, pp. 119-157.

Matsushita, O. et al. (2015), "Effects of Design Thinking on transnational collaborative projects in engineering", 2015 IEEE 7th International Conference on Engineering Education (ICEED), IEEE, pp. 112-117.

Matthews, J.H. and Wrigley, C. (2017), "Design and design thinking in business and management higher education", Journal of Learning Design, Queensland University of Technology, Vol. 10 No. 1, pp. 41-54.

Noweski, C. et al. (2012), "Towards a Paradigm Shift in Education Practice: Developing Twenty-First Century Skills with Design Thinking”, In: Plattner, H., Meinel, C. and Leifer, L. (Eds.), Design Thinking Research: Measuring Performance in Context, Springer Berlin Heidelberg, Berlin, Heidelberg, pp. 71-94.

Ohly, S., Plückthun, L. and Kissel, D. (2016), "Developing Students' Creative Self-Efficacy Based on DesignThinking: Evaluation of an Elective University Course", Psychology Learning \& Teaching, SAGE Publications, Vol. 16 No. 1, pp. 125-132. 
Palacin-Silva, M. et al. (2017), "Infusing Design Thinking into a Software Engineering Capstone Course", 2017 IEEE 30th Conference on Software Engineering Education and Training (CSEE\&T), pp. 212-221.

Parmar, A.J. (2014), "Bridging gaps in engineering education: Design thinking a critical factor for project based learning”, 2014 IEEE Frontiers in Education Conference (FIE) Proceedings, IEEE, pp. 1-8.

Piaget, J. (1954), The Construction Of Reality In The Child, 1st Editio, Routledge, London, available at: https://doi.org/10.4324/9781315009650

Razzouk, R. and Shute, V. (2012), “What Is Design Thinking and Why Is It Important?”, Review of Educational Research, American Educational Research Association, Vol. 82 No. 3, pp. 330-348.

Rhodes, T.L. (2012), "Emerging Evidence on Using Rubrics", Peer Review Published by the Association of American Colleges and Universities, Washington, pp. 4-5.

Rhodes, T.L. and Finley, A. (2013), Using the VALUE Rubrics for Improvement of Learning and Authentic Assessment, Association of American Colleges \& Universities, Association of American Colleges and Universities, Washington, available at: https://www.eou.edu/ctl/files/2012/10/E-VALRUBR2.pdf

Saggar, M. et al. (2017), "Changes in Brain Activation Associated with Spontaneous Improvization and Figural Creativity After Design-Thinking-Based Training: A Longitudinal fMRI Study”, Cerebral Cortex, Vol. 27 No. 7, pp. 3542-3552.

Santos Ordóñez, A. et al. (2017), "Design thinking as a methodology for solving problems: Contributions from academia to society", Proceedings of the LACCEI International Multi-Conference for Engineering, Education and Technology, Vol. 2017-July No. July 2017, pp. 19-21.

Spee, J. and Basaiawmoit, R.V. (2016), "Design Thinking and the Hype Cycle in Management Education and in Engineering Education”, In: Marjanovic, D., Storga, M., Pavkovic, N., Bojcetic, N. and Skec, S. (Eds.), DS 84: Proceedings of the DESIGN 2016 14th International Design Conference, DESIGN SOC, pp. 2111-2124.

Steinbeck, R. (2011), "Building creative competence in globally distributed courses through design thinking", Revista Comunicar, Grupo Comunicar, Vol. 19 No. 37, pp. 27-34.

Strom, P.S., Strom, R.D. and Moore, E.G. (1999), "Peer and self-evaluation of teamwork skills", Journal of Adolescence, Vol. 22 No. 4, pp. 539-553.

Suh, J. et al. (2014), "Critical learning experiences for Korean engineering students to promote creativity and innovation”, 2014 IEEE Frontiers in Education Conference (FIE) Proceedings, IEEE, pp. 1-6.

Taajamaa, V. et al. (2013), "Dancing with ambiguity design thinking in interdisciplinary engineering education", 2013 IEEE Tsinghua International Design Management Symposium, IEEE, pp. 353-360.

Valentim, N.M.C., Silva, W. and Conte, T. (2017), “The Students' Perspectives on Applying Design Thinking for the Design of Mobile Applications", 2017 IEEE/ACM 39th International Conference on Software Engineering: Software Engineering Education and Training Track (ICSE-SEET), pp. 77-86.

Wagner, T. (2010), The Global Achievement Gap: Why Even Our Best Schools Don't Teach the New Survival Skills Our Children Need-and What We Can Do about It, Basic Books, New York.

Wenger, E. (2009), “A social theory of learning”, In: Illeris, K. (Ed.), Contemporary Theories of Learning, Routledge.

West, R.E. et al. (2012), "Innovation 101: Promoting Undergraduate Innovation Through a Two-Day Boot Camp”, Creativity Research Journal, Routledge, Vol. 24 No. 2-3, pp. 243-251. 